\title{
Characterization of $\mathrm{O}_{2}\left({ }^{1} \Delta_{g}\right)$-Derived Oxidation Products of Tryptophan: A Combination of Tandem Mass Spectrometry Analyses and Isotopic Labeling Studies
}

\author{
Graziella Eliza Ronsein, ${ }^{a}$ Mauricio Cesar Bof de Oliveira, ${ }^{\text {a,b }}$ \\ Marisa Helena Gennari de Medeiros, ${ }^{a}$ and Paolo Di Mascio ${ }^{a}$ \\ ${ }^{a}$ Departamento de Bioquímica, Instituto de Química, Universidade de São Paulo, São Paulo, Brazil \\ b Departamento de Polícia Federal, Unidade Técnico-Científica, Delegacia de Ribeirão Preto, Ribeirão Preto, \\ Brazil
}

The fragmentation mechanisms of singlet oxygen $\left[\mathrm{O}_{2}\left({ }^{1} \Delta_{\mathrm{g}}\right)\right]$-derived oxidation products of tryptophan $(\mathrm{W})$ were analyzed using collision-induced dissociation coupled with ${ }^{88} \mathrm{O}$-isotopic labeling experiments and accurate mass measurements. The five identified oxidized products, namely two isomeric alcohols (trans and cis $\mathrm{WOH}$ ), two isomeric hydroperoxides (trans and cis $\mathrm{WOOH}$ ), and $\mathrm{N}$-formylkynurenine (FMK), were shown to share some common fragment ions and losses of small neutral molecules. Conversely, each oxidation product has its own fragmentation mechanism and intermediates, which were confirmed by ${ }^{18} \mathrm{O}-$-labeling studies. Isomeric $\mathrm{WOH}$ lost mainly $\mathrm{H}_{2} \mathrm{O}+\mathrm{CO}$, while $\mathrm{WOOH}$ showed preferential elimination of $\mathrm{C}_{2} \mathrm{H}_{5} \mathrm{NO}_{3}$ by two distinct mechanisms. Differences in the spatial arrangement of the two isomeric WOHs led to differences in the intensities of the fragment ions. The same behavior was also found for trans and cis WOOH. FMK was shown to dissociate by a diverse range of mechanisms, with the loss of ammonia the most favored route. MS/MS analyses, ${ }^{18} \mathrm{O}-$ labeling, and $\mathrm{H}_{2}{ }^{18} \mathrm{O}$ experiments demonstrated the ability of FMK to exchange its oxygen atoms with water. Moreover, this approach also revealed that the carbonyl group has more pronounced oxygen exchange ability compared with the formyl group. The understanding of fragmentation mechanisms involved in $\mathrm{O}_{2}\left({ }^{1} \Delta_{\mathrm{g}}\right)$-mediated oxidation of $\mathrm{W}$ provides a useful step toward the structural characterization of oxidized peptides and proteins. (J Am Soc Mass Spectrom 2009, 20, 188-197) (c) 2009 Published by Elsevier Inc. on behalf of American Society for Mass Spectrometry

$\mathrm{R}$ eactive oxygen species are believed to be formed within cells during aerobic metabolism. Many lines of evidence have linked the oxidative damage generated by these species with the development of pathological conditions, such as atherosclerosis, neurodegenerative diseases, and cancer [1]. Singlet molecular oxygen $\left[\mathrm{O}_{2}\left({ }^{1} \Delta_{\mathrm{g}}\right)\right]$ is a reactive form of oxygen that can be produced by the action of peroxidases [2, 3], UVA light in the presence of a sensitizer $[4,5]$ and also during the dimerization reactions of peroxyl radicals in lipid peroxidation [6, 7]. Electron-rich biomolecules, such as lipids, proteins, and DNA, can be important targets for $\mathrm{O}_{2}\left({ }^{1} \Delta_{\mathrm{g}}\right)$ oxidation [8].

Mass spectrometry (MS) has been applied to the identification of oxidized products resulting from the reaction of reactive oxygen species with a variety of biomolecules. For instance, this technique has been employed to analyze oxidized lipids derived from the Fenton reaction, such as

Address reprint requests to Professor Paolo Di Mascio, Instituto de Química, Departamento de Bioquímica, Universidade de São Paulo, C.P. 26077-CEP 05513-970, São Paulo, SP Brazil. E-mail: pdmascio@iq.usp.br oxidation products of linoleic acid [9], phospholipids [10, 11], and also cholesterol ozonolysis derived products [12]. In DNA, a representative example is $\mathrm{O}_{2}\left({ }^{1} \Delta_{\mathrm{g}}\right)$ oxidation of 2 '-deoxyguanosine, which has been shown to yield 8-oxo7,8-dihydro-2'-deoxyguanosine in double stranded DNA and also other oxidized products upon reaction with an isolated base $[13,14]$.

Detection of oxidized amino acid residues in proteins is a growing field of interest, since accumulation of oxidized proteins in vivo has been related to aging and age-related diseases [15]. Among the common amino acids, tryptophan $(\mathrm{W})$ is considered a highly susceptible residue to oxidizing agents [16, 17]. Many oxidation products of W have been studied by MS. These products include oxindolylalanine (Oia) and dioxindolylalanine [18], generated by the treatment of $\mathrm{W}$ with mixtures of dimethyl sulfoxide and hydrochloric acid in acetic acid and monitored by fast atom bombardment mass spectrometry. Oxindolylalanine and $\mathrm{N}$-acetyloxindolylalanine were also studied by tandem mass spectrometry in a quadrupole ion trap mass spectrometer. These molecules were shown to undergo 
a range of fragmentation reactions, including the loss of water via a number of distinct pathways [19]. Furthermore, hydroxytryptophan, dihydroxytryptophan and/ or $N$-formylkynurenine (FMK) and $\mathrm{W}$-W dimers generated by the Fenton reaction with $W$ were detected by the combination of spin trapping and electrospray mass spectrometry techniques [20]. Electrospray mass spectrometry analyses were also used to propose the formation of FMK as an ozonation product of W [21]. Indeed, the fragmentation pathways of kynurenine $(\mathrm{kn})$ were evaluated using this methodology and deuterium exchange experiments [22].

However, other important oxidation products of $\mathrm{W}$ remain unexplored. This is the case for the products generated by the action of $\mathrm{O}_{2}\left({ }^{1} \Delta_{\mathrm{g}}\right)$ and other oxidizing conditions, such as the addition of a hydroxyl radical to the pyrrole moiety, followed by loss of water and addition of superoxide radical or molecular oxygen [23, 24]. In a previous work, we have shown that tryptophan oxidation by $\mathrm{O}_{2}\left({ }^{1} \Delta_{\mathrm{g}}\right)$ gives rise to cis- and transtryptophan hydroperoxides $(\mathrm{WOOH})$, which can further decompose into the corresponding isomeric alcohols (WOH) and FMK (Scheme 1) [25]. In this study, we explore in depth the use of product and precursor ion spectra, associated with ${ }^{18} \mathrm{O}$-labeling experiments, to derive structural information regarding these oxidation products of $W$.

\section{Experimental}

\section{Materials}

L-Tryptophan $(W)$, deuterium oxide $\left(\mathrm{D}_{2} \mathrm{O}\right), \mathrm{H}_{2}{ }^{18} \mathrm{O}$ (96.9\%), formic acid, and rose bengal were supplied by Sigma Aldrich (St. Louis, MO). The ${ }^{18} \mathrm{O}_{2}$ gas cylinder came from Isotec-Sigma (St. Louis, MO). Acetonitrile (HPLC grade) was purchased from Merck (Rio de Janeiro, Brazil). The water used in the experiments was treated with the Nanopure Water System (Barnstead, Dubuque, IA).

\section{Synthesis of ${ }^{16} \mathrm{O}$ - or ${ }^{18} \mathrm{O}$-Tryptophan Photoproducts}

L-Tryptophan $(20 \mathrm{mM})$ was dissolved in $\mathrm{D}_{2} \mathrm{O}$ containing $10 \mu \mathrm{M}$ rose bengal and irradiated using light from a
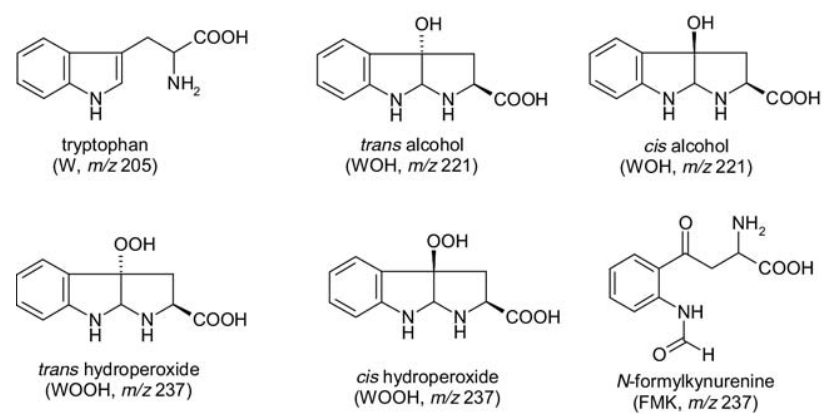

Scheme 1. $\mathrm{O}_{2}\left({ }^{1} \Delta_{\mathrm{g}}\right)$-derived oxidation products of tryptophan. tungsten lamp (500 watt) filtered through a $360 \mathrm{~nm}$ cutoff filter. Irradiation was applied for $3 \mathrm{~h}$ in an ice bath under a continuous flux of oxygen. For the photooxidation in an ${ }^{18} \mathrm{O}_{2}$-saturated atmosphere, oxygen contained in the system was removed by successive freezing and thawing under vacuum. This procedure was repeated at least five times to ensure complete removal of ${ }^{16} \mathrm{O}_{2}$. Thereafter, the whole system was connected to an ${ }^{18} \mathrm{O}_{2}$ gas cylinder under $0.5 \mathrm{~atm}$. After the irradiation, rose bengal was removed by passage through an Acrodisc syringe filter (Pall Gelman, Ann Arbor, MI) with a $0.2 \mu \mathrm{m}$ Supor membrane.

\section{Purification of Photoproducts by HPLC}

The reaction products were purified using a semipreparative C18 reverse-phase column $(250 \times 10 \mathrm{~mm}$, particle size $10 \mu \mathrm{m}$, Phenomenex, Torrance, CA) connected to a Shimadzu HPLC system (Shimadzu, Tokyo, Japan). The separation was carried out at a flow rate of $4.6 \mathrm{~mL} / \mathrm{min}$ with a gradient of water-acetonitrile, using isocratic elution with $2 \%$ acetonitrile for $8 \mathrm{~min}$. Then a linear gradient from $2 \%$ to $6 \%$ in 1 min was employed, maintaining $6 \%$ up to $15 \mathrm{~min}$ and reaching $40 \%$ in the next $3 \mathrm{~min}$. After that, the column was washed with $40 \%$ acetonitrile for $3 \mathrm{~min}$, returning to $2 \%$ in $3 \mathrm{~min}$, followed by column stabilization for another $5 \mathrm{~min}$ at $2 \%$. The product peak fractions were collected and immediately lyophilized.

\section{HPLC/Mass Spectrometry Analysis}

HPLC/MS analyses were carried out in a Shimadzu HPLC system (Tokyo, Japan) coupled to a Quattro II mass spectrometer (Micromass, Manchester, UK) with a $Z$-spray source. The separation of photoproducts was achieved using a $250 \times 4.60 \mathrm{~mm}$ (particle size $5 \mu \mathrm{m}$ ) C18 reverse-phase column (Phenomenex). The mobile phase consisted of $4 \%$ acetonitrile in $0.05 \%$ formic acid at a flow rate of $1.0 \mathrm{~mL} / \mathrm{min}$. A small fraction of the eluent was directed into the mass spectrometer at a flow rate of $100 \mu \mathrm{L} / \mathrm{min}$. Mass spectrometry analyses were done with the electrospray ionizer in the positive ion mode. The source and desolvation temperatures were kept at $100{ }^{\circ} \mathrm{C}$ and $150{ }^{\circ} \mathrm{C}$, respectively. The optimal flow rates of the drying and nebulizing gases were found to be 300 $\mathrm{L} / \mathrm{h}$ and $15 \mathrm{~L} / \mathrm{h}$, respectively. The cone voltage was set at $10 \mathrm{~V}$. Full-scan data were acquired over a mass range 100-500 m/z. Tandem mass spectrometry (MS/MS) experiments were performed for each molecular ion, using the collision energy at $10 \mathrm{eV}$. Also, precursor and product ion scans were conducted on the major ions observed in the MS/MS of unlabeled and ${ }^{18} \mathrm{O}$-labeled $\mathrm{W}$ oxidation products. For this purpose, the most abundant protonated fragments were generated in the ionization source by increasing the cone voltage to $30 \mathrm{~V}$. After that, each of the generated ions was selected and fragmented again, with a collision energy ranging from 
5 to $20 \mathrm{eV}$. Also, the product ions were selected in MS-1 and scanned to identify all of the precursor ions.

\section{Accurate Mass Measurements}

Accurate mass measurements were performed on a micrOTOF electrospray ionization time-of-flight (ESITOF) mass spectrometer (Bruker Daltonics, Billerica, MA). Purified ${ }^{18}$ O-labeled or unlabeled oxidized W derivatives were dissolved in a mixture of $0.01 \%$ formic acid:acetonitrile (1:1) and infused into the mass spectrometer at a flow rate of $180 \mu \mathrm{L} / \mathrm{h}$. The voltage of the capillary was $4 \mathrm{kV}$, the dry gas was kept at $5.0 \mathrm{l} / \mathrm{min}$, and the source temperature was maintained at $160^{\circ} \mathrm{C}$. Calibration of the instrument was achieved through the use of sodium formate. Mass spectra were acquired over a $\mathrm{m} / \mathrm{z}$ range $100-400$.

\section{Oxygen Exchange Experiments}

Purified ${ }^{16} \mathrm{O}-\mathrm{FMK}$ was dissolved in $96.9 \% \mathrm{H}_{2}{ }^{18} \mathrm{O}$ and incubated at $37^{\circ} \mathrm{C}$ with stirring for up to $4 \mathrm{~h}$. This solution was then analyzed by MS/MS.

\section{Results and Discussion}

Photosensitization of $\mathrm{W}$ gives rise mainly to four product peaks with retention times of 5.03, 6.60, 7.92, and $10.28 \mathrm{~min}$ in the UV chromatogram, together with the unreacted $\mathrm{W}$ peak at $21.54 \mathrm{~min}$ (Figure 1). The ion chromatogram obtained by selecting the $\mathrm{m} / \mathrm{z} 221$ reveals that two products have insertions of one oxygen atom in the tryptophan moiety [W $(m / z 205)+16$, Figure $1 b]$, while selection of the $\mathrm{m} / \mathrm{z} 237$ shows three products with insertion of two oxygen atoms $(W+32$, Figure 1c) in the parent molecule. These products were previously characterized as two isomeric alcohols $(\mathrm{m} / \mathrm{z} 221)$, two isomeric hydroperoxides $(\mathrm{m} / \mathrm{z} 237)$ and FMK $(\mathrm{m} / \mathrm{z} 237)$. The cis/trans configurations of the alcohols and hy- droperoxides were established regarding the relative position of the hydroxyl or hydroperoxyl and carboxylic acid groups [25].

Accurate mass measurements were carried out for each $\mathrm{W}$-derived oxidation product synthesized with isotopes 16 and 18 of oxygen. The accurate mass was also determined for the main fragment ions obtained for each labeled or unlabeled photoproduct. The results are summarized in Table 1 . In all cases, the measured masses of the molecular and fragment ions were within $\pm 5 \mathrm{ppm}$ of those expected from the proposed composition.

The tandem mass spectrum obtained for the $[\mathrm{M}+$ $\mathrm{H}]^{+}$molecular ion at $5.03 \mathrm{~min}$ (trans alcohol) is shown in Figure 2a. The cis isomer exhibits almost the same profile (see discussion below). To understand the mechanisms of fragmentation, the two isomeric alcohols were also synthesized with isotope 18 of oxygen. Figure $2 \mathrm{~b}$ shows the successful incorporation of one ${ }^{18} \mathrm{O}$ into the trans alcohol, which then exhibited a molecular ion at $m / z 223$.

Indeed, successive fragment and precursor ion scans were conducted on the major ions observed in the MS/MS of unlabeled and ${ }^{18} \mathrm{O}$-labeled alcohols. For this purpose, protonated fragments were generated in the ionization source. After that, each of the ions was selected and fragmented again, with a collision energy ranging from 5 to $20 \mathrm{eV}$. Also, the product ions were selected in MS-1 and scanned to identify all of the precursor ions. The results of these experiments are illustrated in Scheme 2 for the ${ }^{18} \mathrm{O}$-labeled alcohols. Three fragmentation pathways can be proposed upon analysis of the product and precursor ion scans. The loss of small neutral molecules from the protonated molecular ion or fragments is a common event for all routes. Indeed, the three pathways share some intermediates and final products.

Elimination of $\mathrm{H}_{2} \mathrm{O}$ and $\mathrm{CO}(\mathrm{m} / \mathrm{z} 177$, for the labeled molecule) from the protonated alcohols was the major

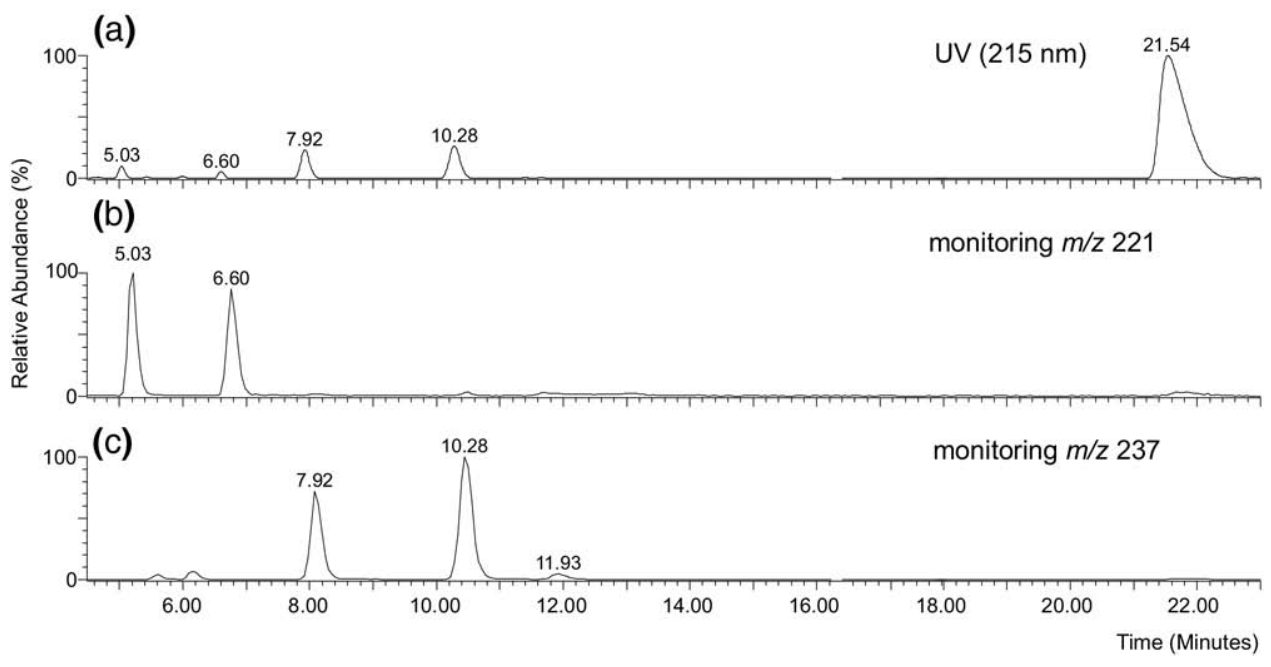

Figure 1. HPLC-ESI/MS obtained after photosensitization of tryptophan. (a) Chromatogram with UV detection at $215 \mathrm{~nm}$. (b) Ion chromatogram selecting $\mathrm{m} / \mathrm{z}$ 221. (c) Ion chromatogram selecting $\mathrm{m} / \mathrm{z} 237$. 
Table 1. Accurate mass measurements of the molecular ions and main fragments obtained for the $\mathrm{O}_{2}\left({ }^{1} \Delta_{\mathrm{g}}\right)$-derived oxidation products of $\mathrm{W}$

\begin{tabular}{|c|c|c|c|c|c|}
\hline Product & Assignment & $\begin{array}{l}\text { Suggested elemental } \\
\text { composition }\end{array}$ & Observed $\mathrm{m} / \mathrm{z}$ & Calculated $\mathrm{m} / \mathrm{z}$ & Error (ppm) \\
\hline \multirow[t]{2}{*}{ trans $\mathrm{WOH}$} & {$[\mathrm{M}+\mathrm{H}]^{+}$} & $\mathrm{C}_{11} \mathrm{H}_{13} \mathrm{~N}_{2}{ }^{16} \mathrm{O}_{3}$ & 221.0924 & 221.0926 & -1.1 \\
\hline & {$\left[\mathrm{M}-\left(\mathrm{CO}, \mathrm{H}_{2} \mathrm{O}\right)+\mathrm{H}\right]^{+}$} & $\mathrm{C}_{10} \mathrm{H}_{11} \mathrm{~N}_{2}{ }^{16} \mathrm{O}$ & 175.0867 & 175.0872 & -2.6 \\
\hline \multirow[t]{2}{*}{ trans $\mathrm{W}^{18} \mathrm{OH}$} & {$[(\mathrm{M}+2)+\mathrm{H}]^{+}$} & $\mathrm{C}_{11} \mathrm{H}_{13} \mathrm{~N}_{2}{ }^{16} \mathrm{O}_{2}{ }^{18} \mathrm{O}$ & 223.0962 & 223.0969 & -3.1 \\
\hline & {$\left[(\mathrm{M}+2)-\left(\mathrm{CO}, \mathrm{H}_{2} \mathrm{O}\right)+\mathrm{H}\right]^{+}$} & $\mathrm{C}_{10} \mathrm{H}_{11} \mathrm{~N}_{2}{ }^{16} \mathrm{O}$ & 177.0906 & 177.0914 & -4.5 \\
\hline \multirow[t]{2}{*}{ cis $\mathrm{WOH}$} & {$[\mathrm{M}+\mathrm{H}]^{+}$} & $\mathrm{C}_{11} \mathrm{H}_{13} \mathrm{~N}_{2}{ }^{16} \mathrm{O}_{3}$ & 221.0933 & 221.0926 & 3.0 \\
\hline & {$\left[\mathrm{M}-\left(\mathrm{CO}, \mathrm{H}_{2} \mathrm{O}\right)+\mathrm{H}\right]^{+}$} & $\mathrm{C}_{10} \mathrm{H}_{11} \mathrm{~N}_{2}{ }^{16} \mathrm{O}$ & 175.0875 & 175.0872 & 2.0 \\
\hline \multirow[t]{2}{*}{$\operatorname{cis} \mathrm{W}^{18} \mathrm{OH}$} & {$[(\mathrm{M}+2)+\mathrm{H}]^{+}$} & $\mathrm{C}_{11} \mathrm{H}_{13} \mathrm{~N}_{2}{ }^{16} \mathrm{O}_{2}{ }^{18} \mathrm{O}$ & 223.0968 & 223.0969 & -0.4 \\
\hline & {$\left[(\mathrm{M}+2)-\left(\mathrm{CO}, \mathrm{H}_{2} \mathrm{O}\right)+\mathrm{H}\right]^{+}$} & $\mathrm{C}_{10} \mathrm{H}_{11} \mathrm{~N}_{2}{ }^{16} \mathrm{O}$ & 177.0911 & 177.0914 & -1.6 \\
\hline \multirow[t]{2}{*}{ trans $\mathrm{WOOH}$} & {$[\mathrm{M}+\mathrm{H}]^{+}$} & $\mathrm{C}_{11} \mathrm{H}_{13} \mathrm{~N}_{2}{ }^{16} \mathrm{O}_{4}$ & 237.0866 & 237.0876 & -4.0 \\
\hline & {$\left[\mathrm{M}-\mathrm{C}_{2} \mathrm{H}_{5} \mathrm{NO}_{3}+\mathrm{H}\right]^{+}$} & $\mathrm{C}_{9} \mathrm{H}_{8} \mathrm{~N}^{16} \mathrm{O}$ & 146.0599 & 146.0606 & -4.7 \\
\hline \multirow[t]{2}{*}{ trans $\mathrm{W}^{18} \mathrm{O}^{18} \mathrm{OH}$} & {$[(\mathrm{M}+4) \mathrm{H}]^{+}$} & $\mathrm{C}_{11} \mathrm{H}_{13} \mathrm{~N}_{2}{ }^{16} \mathrm{O}_{2}{ }^{18} \mathrm{O}_{2}$ & 241.0953 & 241.0960 & -3.1 \\
\hline & {$\left[(\mathrm{M}+4)-\mathrm{C}_{2} \mathrm{H}_{5} \mathrm{NO}_{2}{ }^{18} \mathrm{O}+\mathrm{H}\right]^{+}$} & $\mathrm{C}_{9} \mathrm{H}_{8} \mathrm{~N}^{18} \mathrm{O}$ & 148.0649 & 148.0648 & 0.5 \\
\hline \multirow[t]{2}{*}{ cis $\mathrm{WOOH}$} & {$[\mathrm{M}+\mathrm{H}]^{+}$} & $\mathrm{C}_{11} \mathrm{H}_{13} \mathrm{~N}_{2}{ }^{16} \mathrm{O}_{4}$ & 237.0866 & 237.0876 & -4.0 \\
\hline & {$\left[\mathrm{M}-\mathrm{C}_{2} \mathrm{H}_{5} \mathrm{NO}_{3}+\mathrm{H}\right]^{+}$} & $\mathrm{C}_{9} \mathrm{H}_{8} \mathrm{~N}^{16} \mathrm{O}$ & 146.0599 & 146.0606 & -4.7 \\
\hline \multirow[t]{2}{*}{$\operatorname{cis} \mathrm{W}^{18} \mathrm{O}^{18} \mathrm{OH}$} & {$[(\mathrm{M}+4) \mathrm{H}]^{+}$} & $\mathrm{C}_{11} \mathrm{H}_{13} \mathrm{~N}_{2}{ }^{16} \mathrm{O}_{2}{ }^{18} \mathrm{O}_{2}$ & 241.0958 & 241.0960 & -1.0 \\
\hline & {$\left[(\mathrm{M}+4)-\mathrm{C}_{2} \mathrm{H}_{5} \mathrm{NO}_{2}{ }^{18} \mathrm{O}+\mathrm{H}\right]^{+}$} & $\mathrm{C}_{9} \mathrm{H}_{8} \mathrm{~N}^{18} \mathrm{O}$ & 148.0647 & 148.0648 & -0.9 \\
\hline \multirow[t]{2}{*}{ FMK } & {$[\mathrm{M}+\mathrm{H}]^{+}$} & $\mathrm{C}_{11} \mathrm{H}_{13} \mathrm{~N}_{2}{ }^{16} \mathrm{O}_{4}$ & 237.0872 & 237.0876 & -1.5 \\
\hline & {$\left[\mathrm{M}-\mathrm{NH}_{3}+\mathrm{H}\right]^{+}$} & $\mathrm{C}_{11} \mathrm{H}_{10} \mathrm{~N}^{16} \mathrm{O}_{4}$ & 220.0614 & 220.0610 & 1.8 \\
\hline \multirow[t]{2}{*}{${ }^{18} \mathrm{O}-\mathrm{FMK}$} & {$[\mathrm{M}+\mathrm{H}]^{+}$} & $\mathrm{C}_{11} \mathrm{H}_{13} \mathrm{~N}_{2}{ }^{16} \mathrm{O}_{3}{ }^{18} \mathrm{O}$ & 239.0910 & 239.0918 & -3.3 \\
\hline & {$\left[(\mathrm{M}+2)-\mathrm{NH}_{3}+\mathrm{H}\right]^{+}$} & $\mathrm{C}_{11} \mathrm{H}_{10} \mathrm{~N}^{16} \mathrm{O}_{3}{ }^{18} \mathrm{O}$ & 222.0660 & 222.0652 & 3.4 \\
\hline
\end{tabular}

decomposition pathway. This result is consistent with the fragmentation patterns of the majority of amino acids, which show an initial protonation at the amino group, followed by proton transfer to the carboxylic acid moiety and fragmentation [26]. This common behavior is also in agreement with the "mobile proton model", which describes the dissociation of the molecule as a result of charge-directed cleavages that are initiated by intramolecular proton transfers [27, 28]. Interestingly, the fragmentation pattern of protonated alcohols is in contrast to that of protonated $\mathrm{W}$, which almost exclusively loses $\mathrm{NH}_{3}$ [29].

The major labeled protonated fragment observed for both alcohols $(\mathrm{m} / \mathrm{z} 177)$ was shown to dissociate by three distinct routes. First, this ion loses $\mathrm{C}_{2} \mathrm{H}_{5} \mathrm{~N}$, yielding the labeled protonated ion at $m / z$ 134. Also, $\mathrm{H}_{2}{ }^{18} \mathrm{O}$ is lost, which gives rise to the ion at $m / z 157$, and the molecule further decomposes to the ion at $m / z$ 130. Finally, the protonated fragment at $m / z 177$ eliminates neutral ammonia, generating the ion at $m / z 160$, which yields the ion at $m / z 130$ by the loss of $\mathrm{C}^{18} \mathrm{O}$.

Besides the concomitant loss of $\mathrm{H}_{2} \mathrm{O}$ and $\mathrm{CO}$, the isomeric alcohols also eliminate $\mathrm{H}_{2} \mathrm{O}$. There are two possible sites of water elimination in the alcohol molecules: the hydroxyl oxygen of the carboxylic acid moiety or the alcohol group. The isotopic labeling approach was used to discriminate between these two possibilities. In this way, loss of labeled water from the alcohol moiety would result in a protonated fragment at $\mathrm{m} / \mathrm{z}$ 203. In contrast, elimination of unlabeled water from the carboxylic acid would generate a protonated fragment at $m / z 205$. The result showed that loss of water was

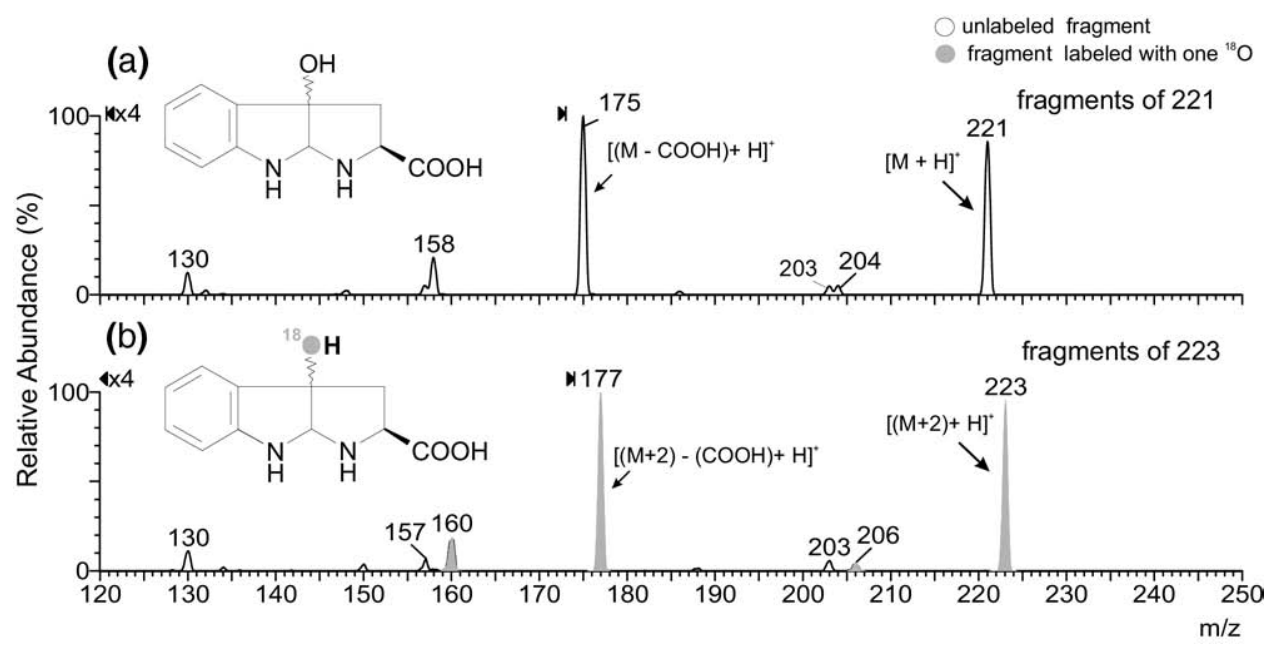

Figure 2. ESI MS/MS of trans alcohol synthesized under ${ }^{16} \mathrm{O}_{2}(\mathbf{a})$ or $(\mathbf{b}){ }^{18} \mathrm{O}_{2}$ atmospheres. 


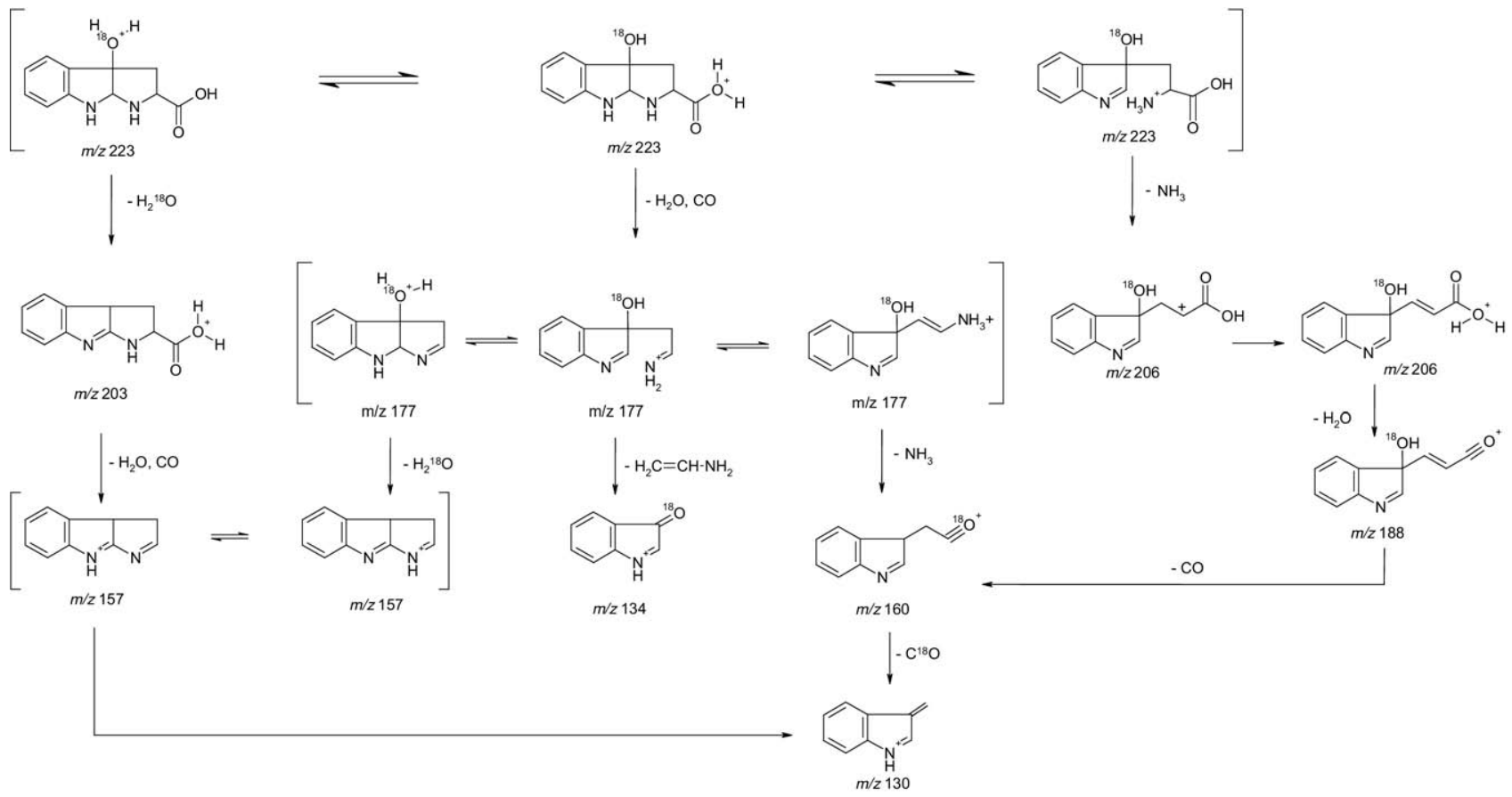

Scheme 2. Proposed fragmentation pathways for ${ }^{18} \mathrm{O}$-labeled alcohols.

exclusively from the alcohol moiety and loss of the hydroxyl oxygen of carboxylic acid moiety was not observed. This behavior was already reported for protonated glycine $[26,30]$. The direct elimination of two neutral species $\left(\mathrm{H}_{2} \mathrm{O}\right.$ and $\left.\mathrm{CO}\right)$ indicates that the intermediate ion is produced near or above the dissociation limit or that it is not a stable species.

The isomeric alcohols show the same fragment ions and the intensity of the ion at $\mathrm{m} / \mathrm{z} 203$ is the most notable difference. This fragmentation process occurs preferentially in the cis alcohol and could be explained considering the differences in the spatial arrangement of these two isomers. In the cis isomer, the distance between the protonated carboxylic acid and the alcohol oxygen could be small and could favor a proton transfer between these two interacting functional groups. The same behavior can also be observed in hydroperoxides, with the loss of hydrogen peroxide favored by the spatial arrangement of the cis isomer.

Finally, loss of $\mathrm{NH}_{3}$ was a minor decomposition route for both alcohols, as judged by the relative intensity of the fragment at $m / z 206$ (or 204 in the case of the unlabeled molecule) (Figure 2 and Scheme 2). Following this decomposition route, the fragment at $\mathrm{m} / \mathrm{z} 206$ undergoes successive cleavages, leading to the fragments at $m / z 188$ (loss of $\mathrm{H}_{2} \mathrm{O}, \mathrm{m} / \mathrm{z} 186$, in the case of the unlabeled molecule) and $160(-\mathrm{CO}, \mathrm{m} / \mathrm{z} 158$, in the case of unlabeled WOH) and finally to the fragment at $\mathrm{m} / \mathrm{z}$ $130\left(-\mathrm{C}^{18} \mathrm{O}\right)$.

In the same way as the isomeric alcohols, trans and cis hydroperoxides, which elute at 7.92 and $10.28 \mathrm{~min}$, respectively, in the UV chromatogram of Figure 1, were analyzed by MS/MS and ${ }^{18} \mathrm{O}$-isotopic labeling. Repre- sentative results are shown in Figure 3a and b, respectively, for unlabeled and ${ }^{18} \mathrm{O}$-labeled trans hydroperoxides. As already discussed above, cis hydroperoxides exhibit the same fragmentation profile, except for the higher intensity of the fragment at $\mathrm{m} / \mathrm{z} 220$ (loss of $\mathrm{H}_{2} \mathrm{O}_{2}$ ), compared with the trans isomer.

Three fragmentation routes can be proposed for hydroperoxides. Two of these routes give rise to the stable ion at $\mathrm{m} / \mathrm{z} 148$ (or 146 in the case of the unlabeled molecule). When analyzing the precursor and fragment ion scans, it is possible to see that the ions at $\mathrm{m} / \mathrm{z} 222$ (or 220 for unlabeled molecule) and 168 (or 166 in the case of $\mathrm{W}^{16} \mathrm{O}^{16} \mathrm{OH}$ ) are precursors of this stable ion (Scheme 3 , the decomposition of ${ }^{18} \mathrm{O}$-labeled hydroperoxides). The chemistry associated with the dissociation of the ion at $m / z 222$ is consistent with a homolytic scission of the peroxide bond, yielding an alkoxyl radical, followed by a rearrangement and loss of an aminyl radical of glycine, generating the ion at $\mathrm{m} / \mathrm{z} 148$. Peroxides have relatively low bond energy compared with average bond energies of oxygen atoms bound to carbon or nitrogen. Consequently, the weak $\mathrm{O}-\mathrm{O}$ bond linkage can be homolytically cleaved [31]. The homolytic scission of the peroxide linkage was previously reported in the electrospray collision-induced fragmentation of the lysine peroxycarbamates [32].

Loss of the immonium form of glycine $\left(\mathrm{C}_{2} \mathrm{H}_{3} \mathrm{O}_{2} \mathrm{~N}\right)$ from the molecular ion, followed by loss of labeled water is the other way to form the ion at $\mathrm{m} / \mathrm{z} 148$. The unlabeled form of this ion $(\mathrm{m} / \mathrm{z} 146)$ has been identified as oxoquinoline, a characteristic fragment of Oia [18, 33]. Nevertheless, the fragmentation profile of the oxoquinolonium ion (protonated oxoquinoline) [18] is dif- 


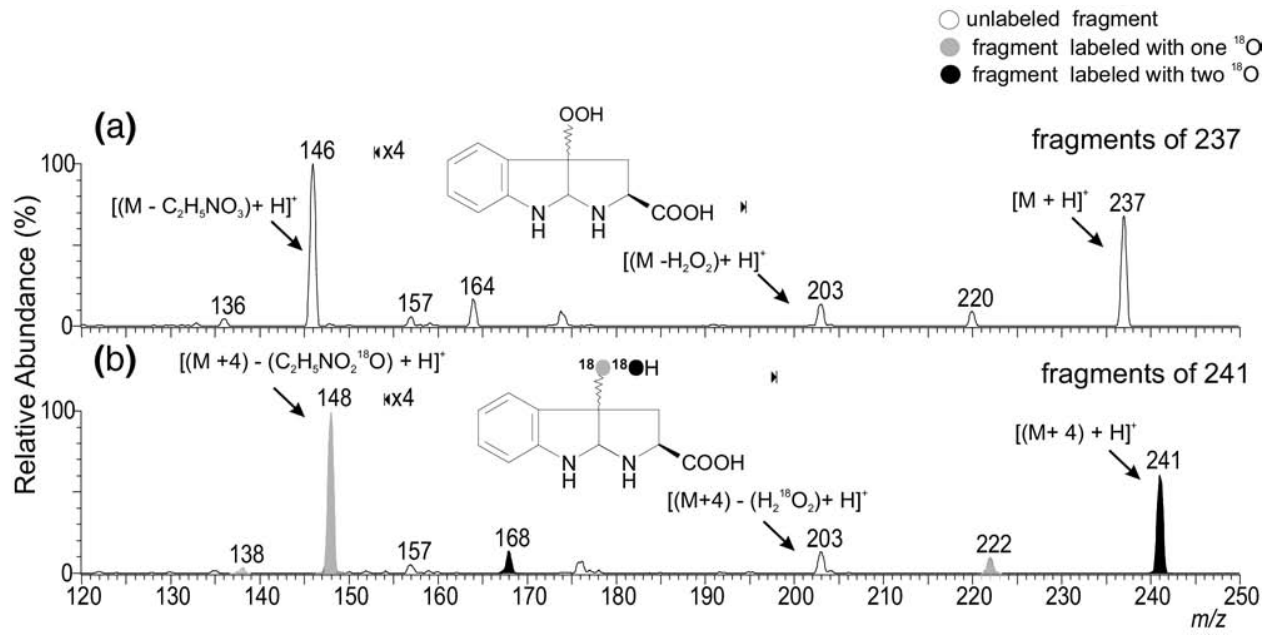

Figure 3. ESI MS/MS of trans hydroperoxide synthesized under ${ }^{16} \mathrm{O}_{2}$ (a) or $(\mathbf{b}){ }^{18} \mathrm{O}_{2}$ atmospheres.

ferent from the fragment at $\mathrm{m} / \mathrm{z} 146$ derived from hydroperoxides. The most abundant ion $(\mathrm{m} / \mathrm{z} 118)$ arising from the former probably corresponds to the elimination of $\mathrm{CO}$, which is consistent with the structure of the oxoquinolonium ion. In contrast, in the case of hydroperoxide, the main ion derived from the fragment at $m / z 146$ corresponds to the elimination of water. The last ion was obtained from the fragmentation of dioxindolylalanine [18]. The proposed structure for this ion is shown in Scheme 3.
The last hydroperoxide fragmentation pathway involves the sequential loss of $\mathrm{H}_{2} \mathrm{O}_{2}$, yielding the ion at $\mathrm{m} / \mathrm{z} 203$, which then exhibits the same fragmentation pattern found for the isomeric alcohols.

Figure $4 \mathrm{a}$ and $\mathrm{b}$ show the fragmentation of FMK molecules synthesized with isotopes 16 and 18 of oxygen, respectively. As previously noted, unlabeled protonated FMK (Figure 4a) exhibits a molecular ion at $\mathrm{m} / \mathrm{z}$ 237. The same ${ }^{18} \mathrm{O}$-isotopic labeling approach used to elucidate the fragmentation pathways of alcohols and

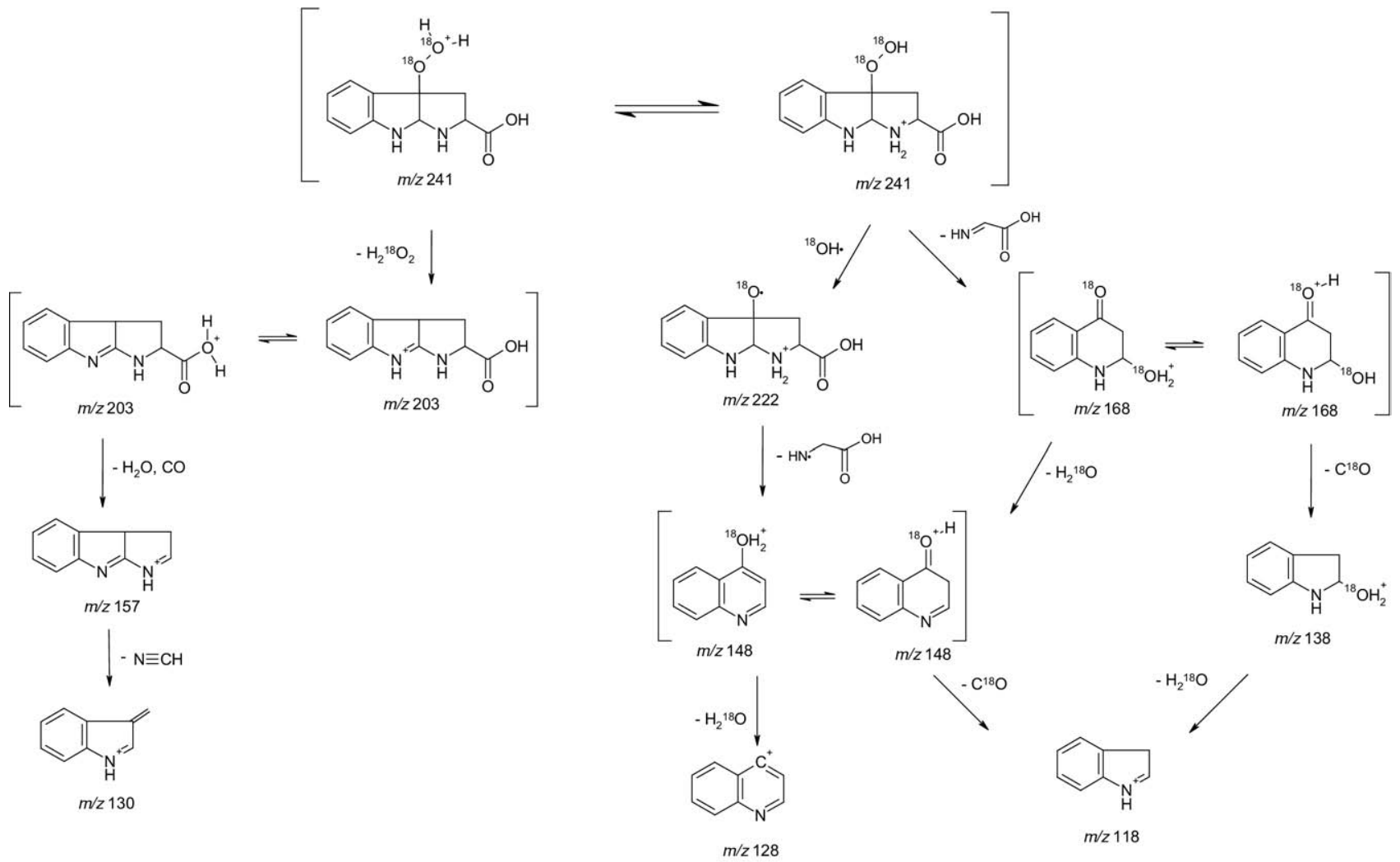

Scheme 3. Proposed fragmentation pathways for ${ }^{18} \mathrm{O}-$ labeled hydroperoxides. 


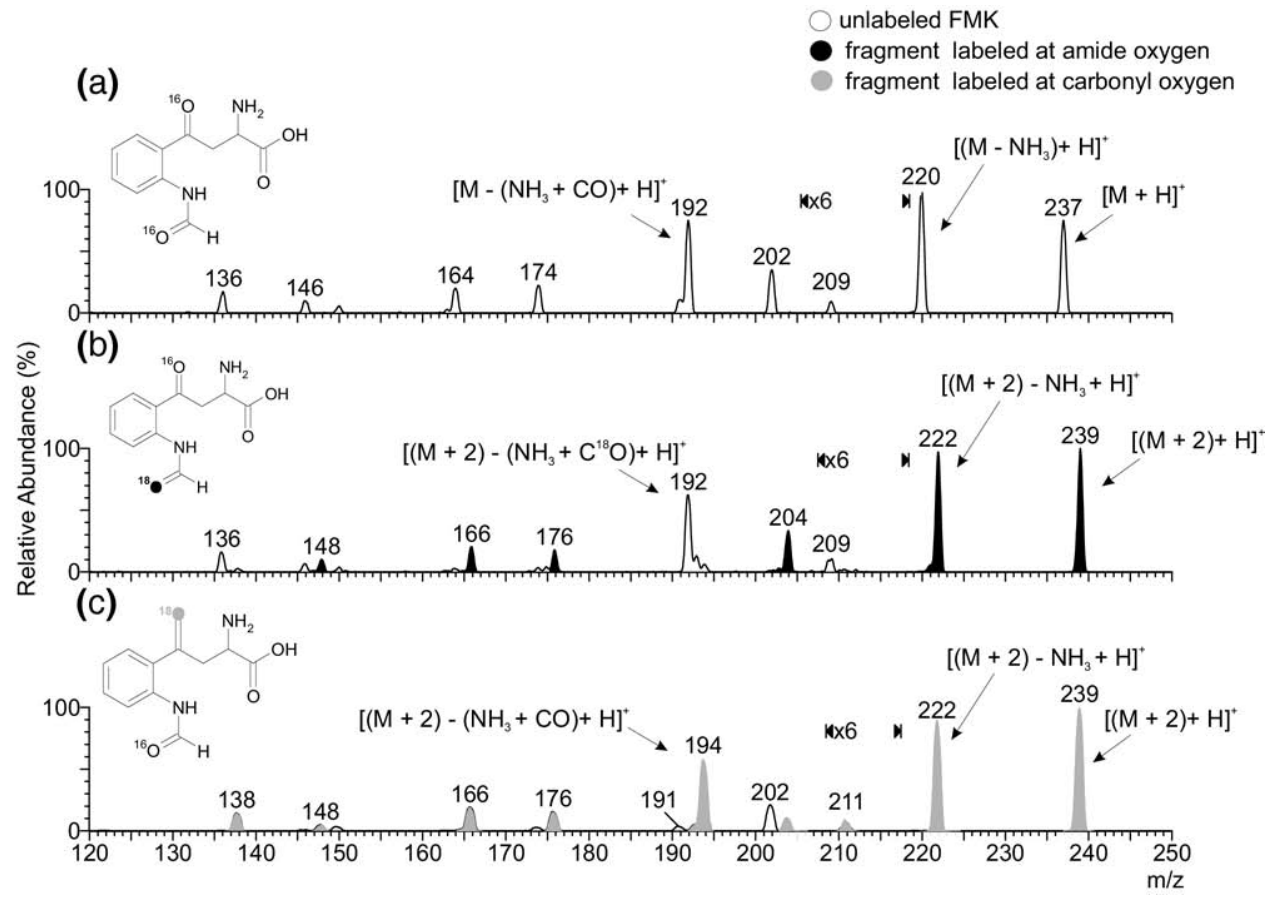

Figure 4. ESI MS/MS of FMK. (a) Fragment ion spectrum of unlabeled FMK. (b) Fragment ion spectrum of ${ }^{18} \mathrm{O}$-labeled FMK. (c) Fragment ion spectrum of unlabeled FMK incubated in the presence of $\mathrm{H}_{2}{ }^{18} \mathrm{O}$.

hydroperoxides was employed for FMK. However, an unexpected problem related to this approach had to be overcome. In contrast to the successful incorporation of two ${ }^{18} \mathrm{O}$ atoms found in $\mathrm{WOOH}(\mathrm{m} / \mathrm{z} 241)$, the mass spectrum of ${ }^{18} \mathrm{O}$-FMK shows a single atom of ${ }^{18} \mathrm{O}(\mathrm{m} / \mathrm{z}$ 239, Figure 4b).

FMK contains carbonyl and amide functional groups. These functional groups have been reported to present high rates of oxygen exchange in water [34-36]. In this way, one can suggest that doubly labeled FMK molecules are able to exchange ${ }^{18} \mathrm{O}$ atoms with solvent molecules, yielding a population of FMK containing just one ${ }^{18} \mathrm{O}$ or even lacking ${ }^{18} \mathrm{O}$ atoms. Thus, another strategy was employed to evaluate the ability of FMK to exchange its oxygen atoms. The strategy consisted of the incubation of unlabeled purified FMK $(\mathrm{m} / \mathrm{z} 237)$ in the presence of $\mathrm{H}_{2}{ }^{18} \mathrm{O}$. The fragment ion spectrum depicted in Figure 4c shows the incorporation of one ${ }^{18} \mathrm{O}$ from labeled water in the FMK moiety. This experiment confirms that FMK is able to exchange oxygen atoms with the solvent. One interesting result is the inversion of some labeled fragments compared with ${ }^{18} \mathrm{O}$-labeled FMK (Figure 4b), showing that the amide and carbonyl fragments have different rates of oxygen exchange (see discussion below).

FMK has already been analyzed by MS [20, 21]. However, using the ${ }^{18} \mathrm{O}$-labeling approach, along with precursor and fragment ion experiments, it is possible to characterize the fragmentation mechanisms of this molecule. In contrast to isomeric $\mathrm{WOH}$ and $\mathrm{WOOH}$, loss of $\mathrm{NH}_{3}(\mathrm{~m} / \mathrm{z} 222$ or 220 in the case of unlabeled molecule) is a favored pathway in the case of FMK. The same fragmentation behavior was obtained with similar molecules, namely W [29] and kn [22], although Oia [19] showed the preferential loss of $\mathrm{H}_{2} \mathrm{O}$ and $\mathrm{CO}$. The different behavior for structurally related molecules shows that small differences in the molecular arrangement, as well as the introduction of some functional groups, can greatly alter the proton affinity of the molecule and also promote charge delocalization in the molecule. This is in agreement with the concepts of the mobile proton model [28], the role of neighboring groups to help cleavage reactions [37], and the fact that fragmentation reactions of protonated amino acids tend to be charge directed $[29,37]$.

Two parallel dissociation pathways can be proposed for the elimination of ammonia from protonated FMK (Scheme 4). First, a cyclized fragment, produced by the nucleophilic attack of the side-chain nitrogen with the $\alpha$-carbon, can be proposed. This proposal is consistent with the concept of the neighboring group facilitating cleavage reactions [37] and was shown to occur in the elimination of ammonia from protonated $W$ [29]. Second, a noncyclized structure, with initial formation of a carbocation, followed by proton transfer to oxygen of carboxylic acid group, can also be proposed. In fact, these two proposed fragmentation routes were based on the fragmentation profile of the deaminated fragment produced from deuterated $\mathrm{kn}$ [22].

Following $\mathrm{NH}_{3}$ loss from protonated FMK, the generated fragment ion at $m / z 222$ (220, unlabeled) shows an initial loss of water followed by elimination of $\mathrm{CO}$, 


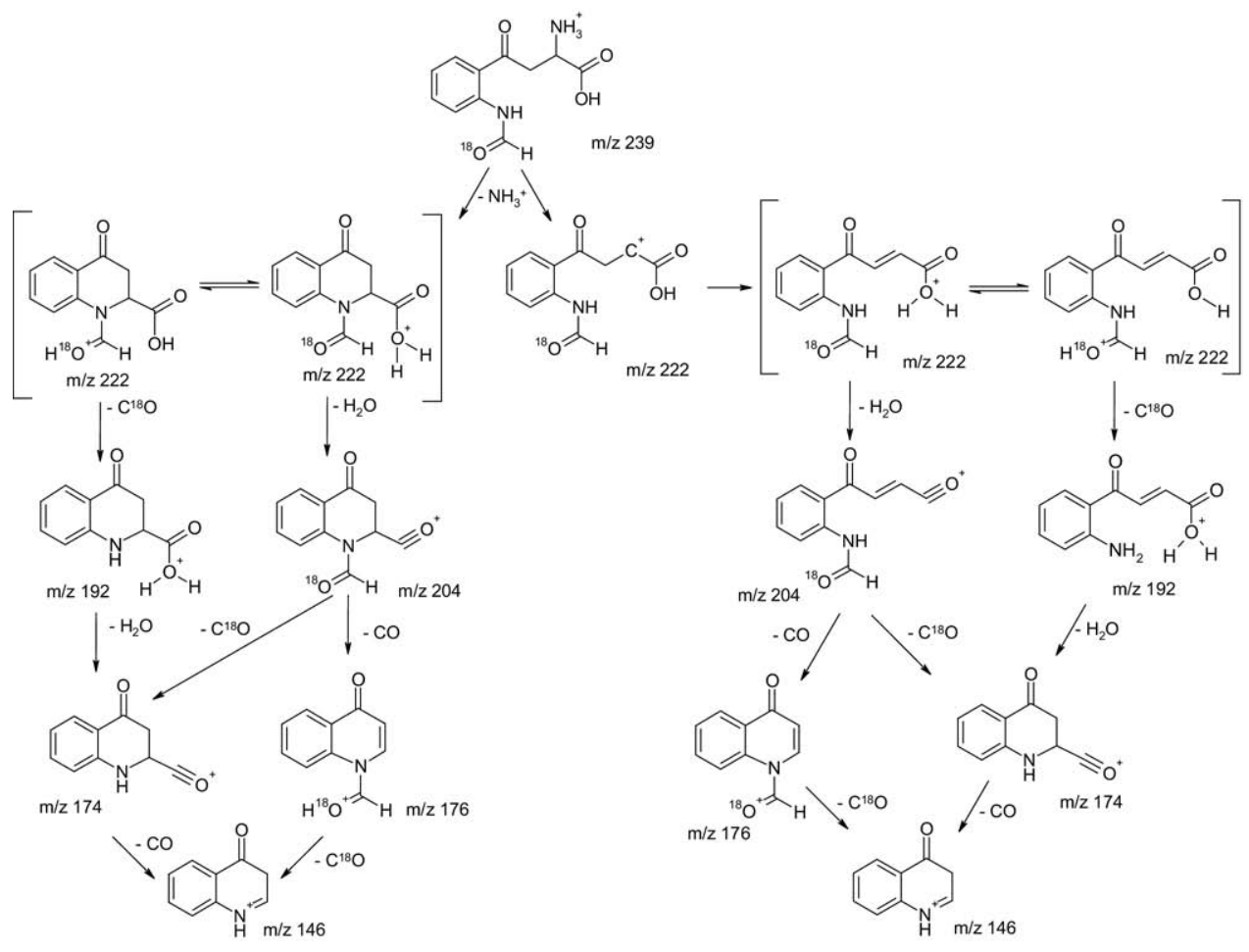

Scheme 4. Main proposed fragmentation pathways for ${ }^{18} \mathrm{O}$-labeled FMK.

yielding the protonated fragments at $\mathrm{m} / \mathrm{z} 204$ (202, unlabeled) and 176 (174, unlabeled) (Scheme 4). These fragmentation patterns are consistent with the maintenance of ${ }^{18} \mathrm{O}$-labeled fragments and corroborate the routes proposed for protonated $\mathrm{kn}$. However, FMK has an additional formyl group compared with kn. For this reason, besides the analogy between the fragmentation pathways of these two molecules, the FMK deaminated fragment was also shown to lose CO. Loss of this neutral CO yields the protonated fragment at $\mathrm{m} / \mathrm{z} 192$ for both labeled and unlabeled FMK. Thus, this fragmentation route appears to refer to the loss of a labeled formyl group from deaminated fragment. Similarly to the protonated fragment at $m / z 222$ (220, unlabeled), the fragment at $\mathrm{m} / \mathrm{z} 192$ also showed successive losses of $\mathrm{H}_{2} \mathrm{O}$ and $\mathrm{CO}$, yielding protonated fragments at $m / z 174$ and 146.

To confirm the ${ }^{18} \mathrm{O}$-labeling in the formyl group, the spectrum obtained with labeled FMK was compared with spectrum obtained upon incubation of unlabeled FMK in the presence of $\mathrm{H}_{2}{ }^{18} \mathrm{O}$ (Figure $4 \mathrm{~b}$ and $\mathrm{c}$ ). In the last case (Figure 4c), it is possible to see the inversion of some labeled fragments in the MS, compared with ${ }^{18} \mathrm{O}$-labeled FMK (Figure $4 \mathrm{~b}$ ). This inversion could be explained by different exchange susceptibilities between carbonyl and amide groups. The former is prone to a nucleophilic attack by water molecules, while the last one is relatively nonreactive due to its resonance stabilization. In this view, if the carbonyl group is more susceptible to oxygen exchanges, labeled FMK will easily change its ${ }^{18} \mathrm{O}$, but the more stable amide group will keep its labeled oxygen atom. On the other hand, in the presence of $\mathrm{H}_{2}{ }^{18} \mathrm{O}$, the amide group of unlabeled FMK will remain unaltered, while the carbonyl oxygen will now display an ${ }^{18} \mathrm{O}$ atom. The explanation was confirmed by MS/MS experiments. For instance, in the case of unlabeled FMK incubated in the presence of $\mathrm{H}_{2}{ }^{18} \mathrm{O}$, loss of ammonia and formyl groups produced a labeled fragment at $m / z 194$ (Figure 4c), instead of an unlabeled fragment at $m / z 192$ for the ${ }^{18} \mathrm{O}$ - labeled molecule (Figure 4b). Also, in the unlabeled FMK maintained in the presence of $\mathrm{H}_{2}{ }^{18} \mathrm{O}$, the direct loss of a formyl group produced a protonated fragment at $\mathrm{m} / \mathrm{z} 211$ (Figure 4c), in contrast to labeled FMK, which displayed a protonated fragment at $m / z 209$ (Figure 4b).

The last fragmentation route observed for FMK is the formation of a protonated ion at $m / z 166$ (or 164 in the case of the unlabeled molecule). The presence of this ion could be explained by the formation of an electrostaticallybound ion molecule complex before elimination of the imine form of glycine (Scheme 5). In fact, this pathway was previously proposed to explain the production of complementary fragment ions from $\mathrm{kn}$ [22]. The use of deuterated $\mathrm{kn}$ supports this conclusion.

Further fragmentation of the labeled protonated ion at $\mathrm{m} / \mathrm{z} 166$ yields the fragment ion at $\mathrm{m} / \mathrm{z} 136$ (loss of $\mathrm{C}^{18} \mathrm{O}$ ). On the other hand, fragmentation of unlabeled FMK incubated in the presence of $\mathrm{H}_{2}{ }^{18} \mathrm{O}$ generates the fragment ion at $m / z 138$ (loss of $\mathrm{CO}$ ), supporting the differences in oxygen exchange susceptibility between carbonyl and amide groups and the formation of the electrostatically-bound ion molecule complex. 


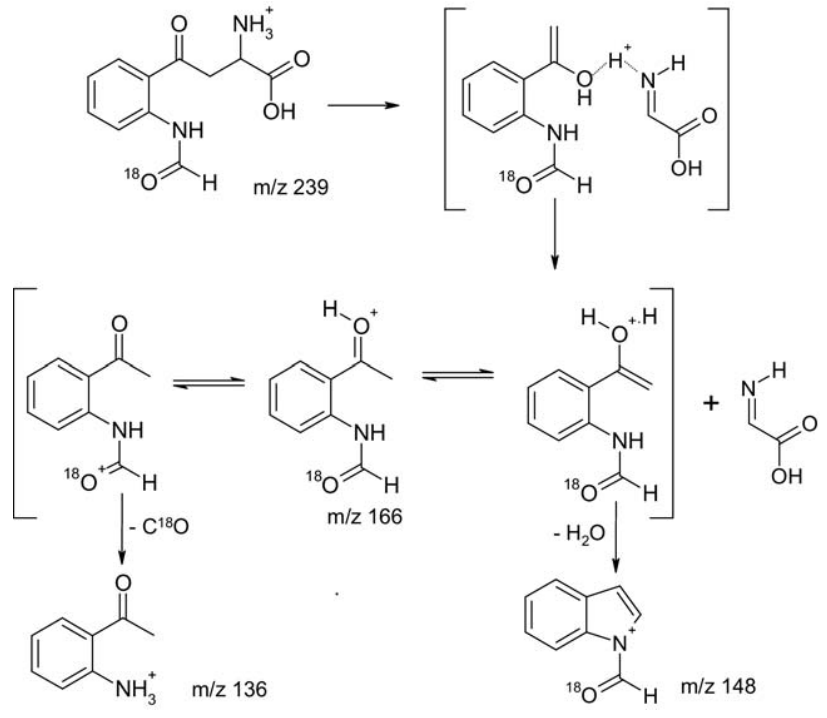

Scheme 5. Proposed fragmentation pathways for ${ }^{18} \mathrm{O}$-labeled FMK via the formation of an ion molecule complex.

\section{Conclusions}

The use of collisional activation reactions, associated with accurate mass measurements and ${ }^{18} \mathrm{O}$-isotopic labeling, has proven to be useful for the structural characterization of $\mathrm{O}_{2}\left({ }^{1} \Delta_{\mathrm{g}}\right)$-derived oxidation products of W. Isomeric alcohols, hydroperoxides, and FMK share some common fragment ions and losses of small neutral molecules, such as $\mathrm{H}_{2} \mathrm{O}, \mathrm{CO}$ and $\mathrm{NH}_{3}$. However, it was shown that small differences in the structure can greatly alter the fragmentation mechanism of structurally related molecules. In this way, tandem mass spectra revealed that each of the $\mathrm{W}$ oxidation products had its own fragmentation mechanism. The most stable fragment ion for isomeric $\mathrm{WOH}$ resulted from concomitant loss of $\mathrm{H}_{2} \mathrm{O}$ and $\mathrm{CO}$. On the contrary, the most stable fragment ion resulting from hydroperoxide dissociation was different. Two distinct routes contribute to yielding this stable fragment ion. The first one results from loss of the immonium form of glycine and water. The other possibility involves the scission of the peroxide bound to yield an alkoxyl radical, which through a rearrangement causes the loss of the aminyl radical of glycine. FMK was shown to dissociate by a diverse range of mechanisms, with the loss of ammonia the most favored route. ${ }^{18} \mathrm{O}$-labeling studies confirmed the fragmentation mechanisms and intermediates. Also, this approach showed the ability of FMK to exchange its oxygen atoms with water. Moreover, MS/MS and $\mathrm{H}_{2}^{18} \mathrm{O}$ experiments demonstrated that the oxygen atom from ketone is more susceptible to exchange with water than the formyl group.

The understanding of dissociation routes of $\mathrm{O}_{2}\left({ }^{1} \Delta_{\mathrm{g}}\right)$ mediated oxidation products of $\mathrm{W}$ reaffirms the importance of fragmentation mechanisms in the structural characterization and provides a useful step toward the analysis of $\mathrm{W}$ oxidation products in peptides and pro- teins. This work can assist in the investigation of oxidized modifications seen in some pathological conditions, such as protein aggregates found in neurodegenerative diseases.

\section{Acknowledgments}

The authors acknowledge financially support for this work by FAPESP - Fundação de Amparo à Pesquisa do Estado de São Paulo, $\mathrm{CNPq}$ - Conselho Nacional para o Desenvolvimento Científico e Tecnológico, and CNPq - Instituto do Milênio, Redoxoma. The authors acknowledge Fernanda Manso Prado and Luzia Emiko Narimatsu for their technical assistance. G.E.R is the recipient of FAPESP fellowship.

\section{References}

1. Hallliwell, B.; Gutteridge, J. M. C. Free Radicals in Biology and Medicine, 4th ed.; Oxford University Press: Oxford, 2007; p. 851.

2. Kanofsky, J. Singlet Oxygen Production by Chloroperoxidase-Hydrogen Peroxide-Halide Systems. J. Biol. Chem. 1984, 259, 5596-5600.

3. Kanofsky, J. Singlet Oxygen Production by Lactoperoxidase. J. Biol. Chem. 1983, 258, 5991-5993

4. Baier, J.; Maisch, T.; Maier, M.; Engel, E.; Landthaler, M.; Baumler, W. Singlet Oxygen Generation by UVA Light Exposure of Endogenous Photosensitizers. Biophys. J. 2006, 91, 1452-1459.

5. Kielbassa, C.; Roza, L.; Epe, B. Wavelength Dependence of Oxidative DNA Damage Induced by UV and Visible Light. Carcinogenesis 1997, 18, 811-816.

6. Miyamoto, S.; Martinez, G. R.; Medeiros, M. H. G.; Di Mascio, P. Singlet Molecular Oxygen Generated from Lipid Hydroperoxides by the Russell Mechanism: Studies Using ${ }^{18}(\mathrm{O})$-Labeled Linoleic Acid Hydroperoxide and Monomol Light Emission Measurements. J. Am. Chem. Soc. 2003, 125, 6172-6179.

7. Miyamoto, S.; Martinez, G. R.; Rettori, D.; Augusto, O.; Medeiros, M. H. G.; Di Mascio, P. Linoleic Acid Hydroperoxide Reacts with Hypochlorous Acid, Generating Peroxyl Radical Intermediates and Singlet Molecular Oxygen. Proc. Natl. Acad. Sci. U.S.A. 2006, 103, 293-298.

8. Straight, R. C.; Spikes, J. D., Photosensitized Oxidation of Biomolecules. In Singlet $\mathrm{O}_{2}$, Frimer, A. A., Ed.; CRC Press: Boca Raton, 1985; p. 91-143.

9. Reis, A.; Domingues, M. R.; Amado, F. M.; Ferrer-Correia, A. J.; Domingues, P. Detection and Characterization by Mass Spectrometry of Radical Adducts Produced by Linoleic Acid Oxidation. J. Am. Soc. Mass Spectrom. 2003, 14, 1250-1261.

10. Reis, A.; Domingues, P.; Ferrer-Correia, A. J.; Domingues, M. R. Tandem Mass Spectrometry of Intact Oxidation Products of Diacylphosphatidylcholines: Evidence for the Occurrence of the Oxidation of the Phosphocholine Head and Differentiation of Isomers. J. Mass Spectrom. 2004, 39, 1513-1522.

11. Reis, A.; Domingues, M. R.; Amado, F. M.; Ferrer-Correia, A. J·; Domingues, P. Radical Peroxidation of Palmitoyl-Lineloyl-Glycerophosphocholine Liposomes: Identification of Long-Chain Oxidized Products by Liquid Chromatography-Tandem Mass Spectrometry. J. Chromatogr. B Analyt. Technol. Biomed. Life Sci. 2007, 855, 186-199.

12. Pulfer, M. K.; Harrison, K.; Murphy, R. C. Direct Electrospray Tandem Mass Spectrometry of the Unstable Hydroperoxy Bis-Hemiacetal Product Derived from Cholesterol Ozonolysis. J. Am. Soc. Mass Spectrom. 2004, 15, 194-202.

13. Martinez, G. R.; Ravanat, J. L.; Cadet, J.; Medeiros, M. H. G.; Di Mascio, P. Spiroiminodihydantoin Nucleoside Formation from 2'Deoxyguanosine Oxidation by $\left[{ }^{18} \mathrm{O}\right.$-Labeled] Singlet Molecular Oxygen in Aqueous Solution. J. Mass Spectrom. 2007, 42, 1326-1332.

14. Ravanat, J.-L.; Di Mascio, P.; Martinez, G. R.; Medeiros, M. H. G.; Cadet, J. Singlet Oxygen Induces Oxidation of Cellular DNA. J. Biol. Chem. 2000, 275, 40601-40604.

15. Stadtman, E. R. Protein Oxidation in Aging and Age-Related Diseases. Ann. N.Y. Acad. Sci. 2001, 928, 22-38.

16. Davies, M. J. The Oxidative Environment and Protein Damage. Biochim. Biophys. Acta 2005, 1703, 93-109.

17. Savige, W. E. New Oxidation-Products of Tryptophan. Aust. J. Chem. 1975, 28, 2275-2287.

18. Van de Weert, M.; Lagerwerf, F. M.; Haverkamp, J.; Heerma, W. Mass Spectrometric Analysis of Oxidized Tryptophan. J. Mass Spectrom. 1998, $33,884-891$.

19. Lioe, H.; O'Hair, R. A.; Reid, G. E. A Mass Spectrometric and Molecular Orbital Study of $\mathrm{H}_{2} \mathrm{O}$ Loss from Protonated Tryptophan and Oxidized Tryptophan Derivatives. Rapid Commun. Mass Spectrom. 2004, 18, 978988.

20. Domingues, M. R. M.; Domingues, P.; Reis, A.; Fonseca, C.; Amado, F. M. L.; Ferrer-Correia, A. J. V. Identification of Oxidation Products and 
Free Radicals of Tryptophan by Mass Spectrometry. J. Am. Soc. Mass Spectrom. 2003, 14, 406.

21. Kotiaho, T.; Eberlin, M. N.; Vainiotalo, P.; Kostiainen, R. Electrospray Mass and Tandem Mass Spectrometry Identification of Ozone Oxidation Products of Amino Acids and Small Peptides. J. Am. Soc. Mass Spectrom. 2000, 11, 526.

22. Vazquez, S.; Truscott, R. J.; O’Hair, R. A.; Weimann, A.; Sheil, M. M. A Study of Kynurenine Fragmentation Using Electrospray Tandem Mass Spectrometry. J. Am. Soc. Mass Spectrom. 2001, 12, 786-794.

23. Hawkins, C. L.; Davies, M. J. Generation and Propagation of Radical Reactions on Proteins. Biochim. Biophys. Acta 2001, 1504, 196-219.

24. Candeias, L. P.; Wardman, P.; Mason, R. P. The Reaction of Oxygen with Radicals from Oxidation of Tryptophan and Indole-3-Acetic Acid. Biophys. Chem. 1997, 67, 229.

25. Ronsein, G. E.; Oliveira, M. C. B.; Miyamoto, S.; Medeiros, M. H. G.; Di Mascio, P. Tryptophan Oxidation by Singlet Molecular Oxygen $\left[\mathrm{O}_{2}\left({ }^{1} \Delta_{\mathrm{g}}\right)\right]$ : Mechanistic Studies Using ${ }^{18} \mathrm{O}$-Labeled Hydroperoxides, Mass Spectrometry, and Light Emission Measurements. Chem. Res. Toxicol. 2008, 21, 1271-1283.

26. Rogalewicz, F.; Hoppilliard, Y.; Ohanessian, G. Fragmentation Mechanisms of $[\alpha]$-Amino Acids Protonated under Electrospray Ionization: A Collisional Activation and $\mathrm{Ab}$ Initio Theoretical Study. Int. J. Mass Spectrom. Ion Processes 2000, 565, 195-196.

27. Dongre, A. R.; Jones, J. L.; Somogyi, A.; Wysocki, V. H. Influence of Peptide Composition, Gas-Phase Basicity, and Chemical Modification on Fragmentation Efficiency: Evidence for the Mobile Proton Model. J. Am. Chem. Soc. 1996, 118, 8365-8374.
28. Harrison, A. G.; Yalcin, T. Proton Mobility in Protonated Amino Acids and Peptides. Int. J. Mass Spectrom. Ion Processes 1997, 339, 165-166.

29. Lioe, H.; O'Hair, R. A. J.; Reid, G. E. Gas-Phase Reactions of Protonated Tryptophan. J. Am. Soc. Mass Spectrom. 2004, 15, 65.

30. Rogalewicz, F.; Hoppilliard, Y. Low Energy Fragmentation of Protonated Glycine. An ab Initio Theoretical Study. Int. I. Mass Spectrom. Ion Processes 2000, 199, 235.

31. Back, R. D., General and Theoretical Aspects of the Peroxide Group. In The Chemistry of Peroxides, Rappoport, Z., Ed.; Wiley and Sons: Chichester, UK, 2006; p. 2-91.

32. Masterson, D. S.; Yin, H.; Chacon, A.; Hachey, D. L.; Norris, J. L.; Porter, N. A. Lysine Peroxycarbamates: Free Radical-Promoted Peptide Cleavage. J. Am. Chem. Soc. 2004, 126, 720-721.

33. Rousseva, L. A.; Gaillard, E. R.; Paik, D. C.; Merriam, J. C.; Ryzhov, V.; Garland, D. L.; Dillon, J. P. Oxindolealanine in Age-Related Human Cataracts. Exp. Eye. Res. 2007, 85, 861.

34. Cohn, M.; Urey, H. C. Oxygen Exchange Reactions of Organic Compounds and Water. J. Am. Chem. Soc. 1938, 60, 679-687.

35. Bender, M. L.; Thomas, R. J. The Concurrent Alkaline Hydrolysis and Isotopic Oxygen Exchange of a Series of P-Substituted Acetanilides. J. Am. Chem. Soc. 1961, 83, 4183-4189.

36. Almeida, E. A.; Martinez, G. R.; Klitzke, C. F.; Medeiros, M. H. G.; Di Mascio, P. Oxidation of Melatonin by Singlet Molecular Oxygen $\left(\mathrm{O}_{2}\left({ }^{1} \Delta_{\mathrm{g}}\right)\right.$ Produces $N^{1}$-Acetyl- $N^{2}$-Formyl-5-Methoxykynurenine. J. Pineal. Res. 2003, 35, 131-137.

37. O'Hair, R. A. J. The Role of Nucleophile-Electrophile Interactions in the Unimolecular and Bimolecular Gas-Phase Ion Chemistry of Peptides and Related Systems. J. Mass Spectrom. 2000, 35, 1377-1381. 